\title{
ANAESTHESIA FOR CAESAREAN SECTION WITH COARCTATION OF AORTA
}

\author{
Deepali Gomase1, Nitin P. Chopde ${ }^{2}$
}

${ }_{1}^{1}$ Senior Consultant, Department of Anaesthesia, Ganga Care Hospital, Nagpur, Maharashtra, India.

${ }^{2}$ Consultant, Department of Anaesthesia, Ganga Care Hospital, Nagpur, Maharashtra, India.

HOW TO CITE THIS ARTICLE: Gomase D, Chopde NP. Anaesthesia for caesarean section with coarctation of aorta. J. Evolution Med. Dent. Sci. 2018;7(28):3264-3265, DOI: 10.14260/jemds/2018/735

\section{PRESENTATION OF CASE}

Our patient 28 years old was admitted with amenorrhea, 30 weeks and pain abdomen. She was a diagnosed case of coarctation of aorta and balloon dilatation done nearly 7 years back and gradient was decreased to $30 \mathrm{mmHg}$. Again, she underwent balloon dilatation 8 months back. She came for check-up when she was 3 months pregnant and noticed gradient increasing. Patient was put on tablet amlodipine $2.5 \mathrm{mg} \mathrm{BD}$ and tablet Nicardia $10 \mathrm{mg}$ BD. Patient was evaluated by cardiologist after admission and gradient was found to be increased to $70 \mathrm{mmHg}$. Patient was decided to take for emergency LSCS.

On clinical examination her heart rate was 84 per minute, blood pressure was 130/86 and 128/84 in right and left upper limb respectively and 126/90 and 130/84 in right and left lower limb. Sp02 was 99\% in all extremities. This shows circulation still maintained through collaterals. After painting and draping, patient was induced with IV propofol $120 \mathrm{mg}$ and succinylcholine $75 \mathrm{mg}$. Patient was intubated with 7 no. ETT. Patient was maintained with propofol infusion and midazolam and fentanyl was given after delivery. A continuous infusion of propofol (100 - 300 $\mu \mathrm{g} / \mathrm{kg} / \mathrm{hr}$ ) was used to maintain adequate depth of anaesthesia. A live $2.5 \mathrm{~kg}$ baby was delivered with good Apgar score. Pitocin was continued through drips. Patient was extubated uneventfully. Esmolol boluses was given to control heart rate and blood pressure during extubation. Analgesia was provided with Inj. diclofenac and paracetamol. Patient was shifted to ICU for observation and to ward the next day.

We report a case of a patient with coarctation of aorta with balloon dilatation done, but still having a high gradient presented for emergency caesarean section [LSCS]. Preoperative management focused on minimising haemodynamic disturbances. Good oxygenation means good foetal perfusion and good perfusion of vital organs. During pregnancy, there is a risk of aortic dissection or intracranial haemorrhage. Maternal mortality may be as high as $3-8 \%$, even in those who have undergone repair. Thus, all pregnancies should be treated as high risk.

Coarctation literally means drawing together and is narrowing of the aorta.[1] It usually occurs distal to the left subclavian artery. In recent years alternative treatment of coarctation of aorta have been developed, therefore

'Financial or Other Competing Interest': None.

Submission 04-05-2018, Peer Review 25-06-2018,

Acceptance 01-07-2018, Published 09-07-2018.

Corresponding Author:

Dr. Nitin P. Chopde,

\#91, Ganga Sona Apartment,

Old Subhedar Layout Extension,

Nagpur, Maharashtra, India.

E-mail: nitin4anaesthesia@gmail.com

DOI: $10.14260 /$ jemds $/ 2018 / 735$

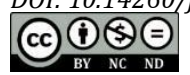

a number of women who reach childbearing age with coarctation has been increased.[2] Adverse neonatal effects such as growth retardation, abruptio placentae and premature delivery are concerns in these population. ${ }^{[3]}$

\section{DISCUSSION OF MANAGEMENT}

About 6 - 8\% of patients with congenital heart disease were found to have coarctation of aorta at thoracic inlet. Males were more affected.[4] Several changes happen during pregnancy and need special care, especially in females with coarctation. Chances of risk of aortic rupture or dissection increases during pregnancy, secondary to changes in aortic wall, aortopathy and long-standing hypertension.

Good outcome during pregnancy is said if systolic blood pressure difference in upper and lower limb is $<20 \mathrm{mmHg}$. ${ }^{[5]}$ From third to the seventh month of pregnancy, circulation is successively accelerated and blood volume and cardiac output increases by $30-50 \%$. The blood pressure balance shows sudden changes in seventh month of pregnancy. Due to these haemodynamic changes, the risk of complication like dissection or congestive cardiac failure increases in late pregnancy or within six weeks postpartum. ${ }^{[6]}$ Foetal mortality rate also increases and can reach upto $20 \%$ as uterine perfusion decreases distal to coarctation end. Even patients with repaired coarctation have increased chances of rupture of cerebral aneurysm and aortic dissection in third trimester and peripartum period. This may be related to hormonal and haemodynamic changes.[7] Blood pressure control is a must, otherwise effects on neonate (growth retardation, abruptio placentae and premature delivery) and maternal (renal failure, hypertensive crisis) are observed.[8] After this second critical period is in labour itself, as blood pressure and cardiac output increases by $20 \%$ during each uterine contraction. [9] Beta blockers can be used in this condition. Although, beta blockers increases the chance of foetal growth retardation, maternal blood pressure control is to be done with priority. Even calcium channel blockers and ACE inhibitors cause precipitous fall in blood pressure and therefore contraindicated. Some suggested that ACE inhibitors should be discontinued before conception, as they may have teratogenic effects.[6] The anaesthetic goal is to maintain normal or slightly elevated SVR and heart rate, while taking care to keep the intravascular volume adequate. Though, elective LSCS is recommended, recent European Society of Cardiologist Guidelines suggest vaginal delivery under epidural is the safer mode.[10] For caesarean section we preferred general anaesthesia, but chances of aortic rupture are high during intubation. Even respiratory depression is seen in parturient and neonate due to opioids. So, remifentanil is the better choice of opioid here.[11] General anaesthesia with remifentanil for LSCS with critical heart disease with good Apgar score has been mentioned.

Epidural anaesthesia is preferred by some, as it does not cause precipitous fall in blood pressure. Spinal anaesthesia 
may lead to afterload reduction, hypotension and tachycardia which is unacceptable in such cases, although some cases said that guarded spinal is preferred.

Even some use CSEA with low spinal drug and titrated with increased dose through epidural.[12,13]

We preferred general anaesthesia in view of an emergency LSCS for foetal distress. We preferred noninvasive monitoring in all extremities, as was not having much time in hand to detect any compromise in placental circulation. Oxygen saturation was maintained between 97 $99 \%$ in both upper and lower limbs. Oxygen saturation in the lower limbs maintained indicates good perfusion below the coarctation. We preferred propofol infusion for maintenance, as inhalational agent causes uterine relaxation and we cannot give oxytocin fast in such cases. Oxytocin should be given at lowest effective dose and infusion form. Increased uterine contraction to oxytocin can easily lead to heart failure. Ephedrine and dopamine can be used for their positive chronotropic effect. In our case, there was no need of use of vasopressors, as small fall in blood pressure was within acceptable levels. Also urine output was well maintained.

\section{CONCLUSION}

Women with a history of coarctation of the aorta should have close haemodynamic monitoring throughout pregnancy. Early discussion between cardiologists, obstetricians and anaesthetists will allow planned management of pregnancy and delivery. The uneventful course of anaesthesia was related to thorough systemic evaluation and careful anaesthetic strategy.

\section{REFERENCES}

[1] Grewal J. Coarctation of the aorta - anesthesia tutorial of the week 265. 23RD July 2012: p. 1-11.

[2] Maitra G, Sengupta S, Rudra A, et al. Pregnancy \& nonvalvular heart disease - anesthetic considerations. Ann Card Anaesth 201;13(2):102-9.

[3] Beauchesne LM, Connolly HM, Ammash NM, et al. Coarctation of the aorta: outcome of pregnancy. J Am Coll Cardiol 2001;38(6):1728-33.
[4] Beckman RH III. Coarctation of the aorta. In: Allen HD, Gutgesell HP, Clark EB, et al. eds. Moss and Adams' heart disease in infants, children and adolescents: including the fetus and young adult. Vol. 2. $6^{\text {th }}$ edn. Philadelphia, PA: Lippincott Williams \& Wilkins 2001: p. 988-1010.

[5] Saidi AS, Bezold LI, Altman CA, et al. Outcome of pregnancy following intervention for coarctation of the aorta. Am J Cardiol 1998;82(6):786-8.

[6] Bengali R, Patil T. Coarctation of aorta \& Takayasu arteritis for LSCS: anaesthesia management. JEMDS 2015;4(82):14427-31.

[7] Sherer DM. Coarctation of the descending thoracic aorta diagnosed during pregnancy. Obstet \& Gynaecol 2002;100(5 Pt 2):1094-6.

[8] Barno A, Freeman DW. Maternal deaths due to spontaneous subarachnoid hemorrhage. AM J Obstet \& Gynecol 1976;125(3):384-92.

[9] Yavuz C, Soydinc HE, Tekbas G. Pregnancy complicated with severe recurrent aortic coarctation: a case report. Case Rep Vasc Med 2012;2012:865035.

[10] Regitz-Zagrosek V, Lundqvist BC, Borghi C, et al. ESG guidelines on management of cardiovascular disease during pregnancy: The Task Force on the Management of cardiovascular diseases during pregnancy of the European Society of Cardiology (ESC). Eur Heart J 2011;32(24):3147-97.

[11] Manullang TR, Chun K, Egan TD. The use of remifentanil for caesarean section in a parturient with recurrent aortic coarctation. Canadian Journal of Anesthesia 2000;47(5):454-9.

[12] Walker E, Malins AF. Anaesthetic management of aortic coarctation in pregnancy. International Journal of Obstet Anaesth 2004;13(4):266-70.

[13] Ubale PV, Kane DD. Non-invasive monitoring in pregnant patient with coarctation of aorta undergoing caesarean section. Bombay Hospital Journal 2011;53(3):665-8. 